\title{
National Geospatial Program
}

The National Geospatial Program (NGP; http://www.usgs.gov/ngpo/) satisfies the needs of customers by providing geospatial products and services that customers incorporate into their decisionmaking and operational activities. These products and services provide geospatial data that are organized and maintained in cost-effective ways and developed by working with partners and organizations whose activities align with those of the program. To accomplish its mission, the NGP-

- organizes, maintains, publishes, and disseminates the geospatial baseline of the Nation's topography, natural landscape, and manmade environment through The National Map

- fosters a general understanding of broad geographic patterns, trends, and conditions through The National Atlas of the United States of America

- increases the efficiency of the Nation's geospatial community by improving communications about geospatial data, products, services, projects, needs, standards, and best practices

The NGP comprises seven major components (described below), that are managed as a unified set. For example, The National Map establishes data standards and identifies geographic areas where specific types of geospatial data need to be incorporated into The National Map. Partnership Network Liaisons work with Federal, State, local, and tribal partners to help acquire the data. Geospatial technical operations ensure the quality control, integration, and availability to the public of the data acquired. The Emergency Operations Office provides the requirements to The National Map and, during emergencies and natural disasters, provides rapid dissemination of information and data targeted to the needs of emergency responders. The National Atlas uses data from The National Map and other sources to make small-scale maps and multimedia articles about the maps.

\section{The National Map}

The National Map (http://nationalmap.gov) is a suite of products and services that provide access to base geospatial information to describe the landscape of the United States and its territories. The National Map embodies 11 primary products and services and numerous applications and ancillary services. The National Map supports data download, digital and print versions of topographic maps, geospatial data services, and online viewing. Customers can use geospatial data and maps to enhance their recreational experience, make life-saving decisions, support scientific missions, and for countless other activities. Nationally consistent geospatial data from The National Map enable better policy and land management decisions and the effective enforcement of regulatory responsibilities.

The National Map is easily accessible for display on the Web through such products as topographic maps and services and as downloadable data. The geographic information available from The National Map includes boundaries, elevation, geographic names, hydrography, land cover, orthoimagery, structures, and transportation. The majority of The National Map effort is devoted to acquiring and integrating medium-scale (nominally 1:24,000 scale) geospatial data for the eight base layers (fig. 1) from a variety of sources and providing access to the resulting seamless coverages of geospatial data. The National Map also serves as the source of base mapping information for derived cartographic products, including 1:24,000 scale US Topo maps and georeferenced digital files of scanned historic topographic maps. Datasets and products from The National Map are intended for use by government, industry, and academia - focusing on geographic information system (GIS) users - as well as the public, especially in support of recreation activities. Other types of georeferenced or mapping information can be added within The National Map Viewer or brought in with The National Map data into a GIS to create specific types of maps or map views and (or) to perform modeling or analyses.

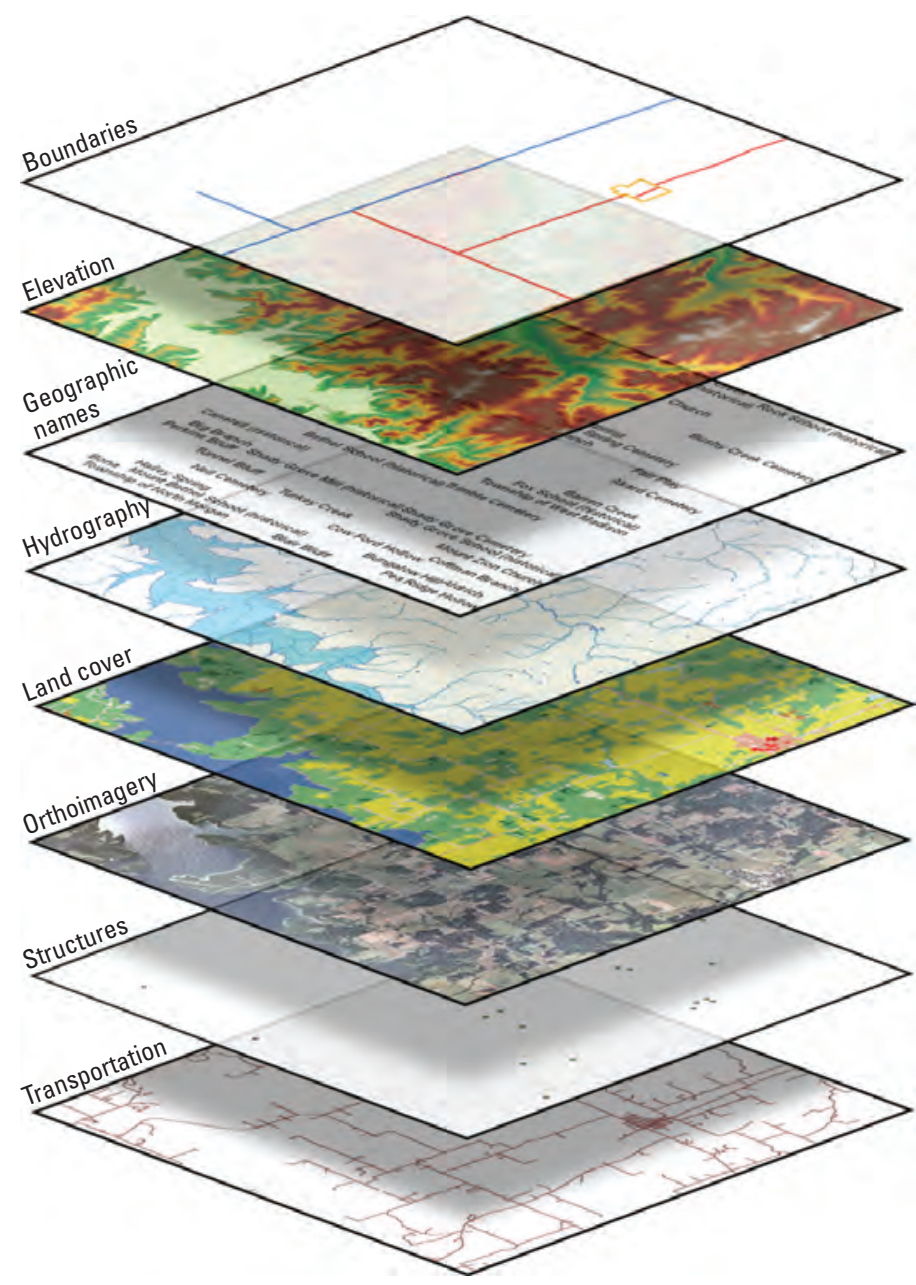

Figure 1. Eight base layers of The National Map. 


\section{The National Atlas of the United States ${ }^{\circledR}$}

The National Atlas (http://nationalatlas.gov/) uses datasets of a highly generalized framework from The National Map as the cartographic foundation for thousands of thematic maps. More than two dozen Federal agencies collaborate in the National Atlas to provide accurate, integrated, and reliable geospatial information about the Nation's natural and socioeconomic landscapes. Most National Atlas products are clearly designed for public use and include wall maps, innovative page-sized printable maps, and an interactive mapmaker for crafting custom maps. The National Atlas also includes multimedia articles about National Atlas maps as well as maps that illustrate how the Nation changes. All National Atlas data are fully documented and are provided at no cost for download or direct use on the Web. The data available from the National Atlas are provided at a scale where 1 inch on the map is roughly 16 miles. For geographic information professionals, the National Atlas offers documented small-scale geospatial data and Web map services that are integrated with similar data and services from Canada and Mexico to create the North American Environmental Atlas (http://www.cec.org/ naatlas/) and contribute to the Share the Global Map project (http://www.globalmap.org/english/index.html).

\section{Partnership Activities}

NGP partnerships provide significant cost savings, reduce redundancy in geospatial data acquisition and stewardship, and ensure availability of common base data to a broad range of users and applications. The NGP Partnership Network (http://liaisons.usgs.gov/geospatial/) comprises headquarters liaisons, who coordinate with Federal agencies and national organizations, and State-based U.S. Geological Survey (USGS) geospatial liaisons, who are distributed across the Nation to coordinate efforts of the USGS and other Federal entities with State, local, and tribal groups. Liaisons work with these organizations to identify geospatial data requirements and standards; evaluate partnership opportunities; develop agreements; participate in State, regional, and local geospatial data councils; and provide outreach to communities of users. Many of these organizations produce and maintain a vast array of current, accurate geospatial data. As a result, a large majority of data in The National Map is the product of jointly funded partnership agreements aligned with the goals of the NGP. In addition to providing cost savings across participating organizations and reducing redundancy, these partnership activities support coordination and training at the State and national levels and help to advance the National Spatial Data Infrastructure (NSDI; http://www.fgdc.gov/nsdi/nsdi.html).

\section{Geospatial Technical Operations}

Geospatial technical operations efforts by the National Geospatial Technical Operations Center (NGTOC; http://ngtoc.usgs.gov/) and the Earth Resources Observation Science (EROS) Center (http://eros.usgs.gov/) focus on developing and enhancing the usefulness of geospatial products and services; acquiring new geospatial data; assessing the geospatial data for accuracy, quality, and integration into nationwide datasets; archiving raster and vector imagery; and improving public access to the acquired geospatial data through online viewing and data downloading. The NGTOC and the EROS Center also perform research and development into new processes and technology in the implementation of The National Map, and a critical role is providing technical services to assist NGP partners in the acquisition and maintenance of geospatial data that become part of The National Map. Finally, the NGTOC and the EROS Center develop interfaces and provide access to The National Map products, such as US Topo.

\section{Emergency Operations}

The Emergency Operations Office (http://www.usgs.gov/ emergency/) ensures coordination and rapid availability of data from The National Map and other geospatial information for effective response to natural and other disasters by emergency responders, land and resource managers, and scientists. Procedures are established for acquisition, processing, and archiving of nonproprietary geospatial data; discovery, access, and delivery of data; and for providing relevant geospatial products and services during and immediately after emergency events. These activities enable interdisciplinary integration of government assets to improve the value of data and services to responders and citizens in cases of emergency. The Emergency Operations Office leverages the Partnership Network and partnerships with the Department of Homeland Security, the National GeospatialIntelligence Agency, the United States Northern Command, and the National Guard Bureau to coordinate the provisioning and deployment of USGS geospatial data, products, services, and equipment.

\section{Geospatial Information Science Research}

Geospatial research is conducted by the Center of Excellence for Geospatial Information Science (CEGIS; http://cegis. usgs.gov/), which identifies and collaborates on geographic information science research issues of national importance. CEGIS basic research activities are guided by the published recommendations of the National Academy of Sciences and priorities are established by the NGP management team based on long-term program direction and goals. Most CEGIS basic research efforts are in support of The National Map, but also include investigation of emerging technologies (such as the semantic Web and social media) and their effects on the NSDI and the emerging geospatial Web.

\section{Board on Geographic Names Secretariat}

The NGP provides the secretariat and staff for the U.S. Board on Geographic Names (BGN; http://geonames.usgs.gov/), a Federal interagency body empowered by Public Law 80-242 (61 Stat. 456) to approve and issue standard geographic names for use on all material (maps, documents, reports, data files) published by the Federal Government and its contractors. A large number of State agencies and local and tribal organizations also adhere to the guidelines and policies of the BGN and participate actively in the standardization effort.

By William J. Carswell, Jr. 